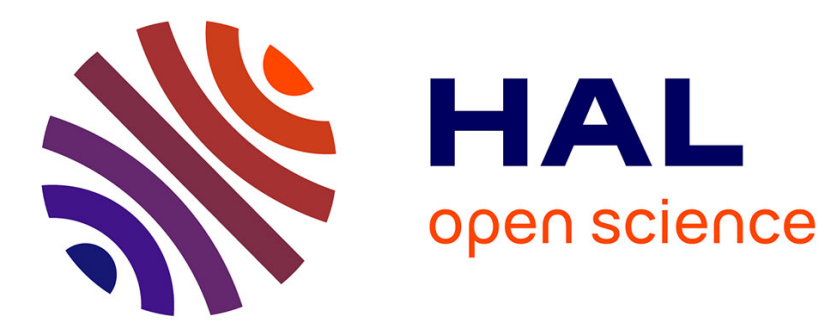

\title{
The efficiency of congestion charging: Some lessons from cost-benefit analyses
}

Charles Raux, Stéphanie Souche, Damien Pons

\section{To cite this version:}

Charles Raux, Stéphanie Souche, Damien Pons. The efficiency of congestion charging: Some lessons from cost-benefit analyses. Research in Transportation Economics, 2012, 36 (1), pp.85-92. 10.1016/j.retrec.2012.03.006 . halshs-01026428

\section{HAL Id: halshs-01026428 \\ https://shs.hal.science/halshs-01026428}

Submitted on 3 Nov 2014

HAL is a multi-disciplinary open access archive for the deposit and dissemination of scientific research documents, whether they are published or not. The documents may come from teaching and research institutions in France or abroad, or from public or private research centers.
L'archive ouverte pluridisciplinaire HAL, est destinée au dépôt et à la diffusion de documents scientifiques de niveau recherche, publiés ou non, émanant des établissements d'enseignement et de recherche français ou étrangers, des laboratoires publics ou privés. 


\title{
THE EFFICIENCY OF CONGESTION CHARGING: SOME LESSONS FROM COST-BENEFIT ANALYSES
}

\author{
Charles RAUX*, Stéphanie SOUCHE, Damien PONS \\ Laboratoire d'Economie des Transports \\ (CNRS, Université de Lyon)
}

* corresponding author

Address:

LET, ISH, 14 avenue Berthelot, 69363 LYON Cedex 07, France.

Email: charles.raux@let.ish-lyon.cnrs.fr

Tel: +33472726454

Fax: +33472726448

\begin{abstract}
:
This paper addresses methodological issues in cost-benefit analysis (CBA) regarding congestion charging schemes. Despite suspicion on the reality of travel time savings, it is argued that these savings are a conservative value of surplus gained from a congestion scheme. The methodology of measurement of travel time reliability is not yet stabilised, but the literature review suggests that it may take a growing share of benefits in the future. Sensitivity tests performed on the London and Stockholm case studies with a simulation model underline the need to accurately measure speeds, while the value of travel time appears less critical. Finally, the impact of costs of public funds on public accounts is greatly significant and may increase in the future.
\end{abstract}

Keywords: cost-benefit analysis, congestion charging, travel time savings, London, Stockholm, cost of public funds.

Réf : Raux Souche Pons Submission to Retrec - 02/04/2012. Raux C., Souche S., Pons D. (2012), "The efficiency of congestion charging: Some lessons from cost-benefit analyses", Research in Transportation Economics, Vol. 36, $n^{\circ}$. 1, p. 85-92. Doi 10.1016/j.retrec.2012.03.006. 


\section{INTRODUCTION}

The apparent success of both the London Congestion Charging Scheme which started in 2003 (Leape, 2006; Santos and Fraser, 2006) and the Stockholm trial in 2006 (Eliasson, 2008), followed by a durable implementation in 2007, fosters the interest of other cities in the world toward urban road pricing.

Economists have long advocated congestion charging on the grounds of its economic efficiency. However, the debate about the economic efficiency of these schemes has been subject to some controversy (Prud'homme and Bocarejo, 2005; Mackie, 2005; Raux, 2005; Prud'homme and Kopp, 2010), which casts some doubt on the intrinsic efficiency of congestion charging as predicted by the theory: in particular transaction costs may undermine the benefits of the scheme.

The effective implementation of road pricing especially in urban areas raises not only the economic efficiency but also other issues such as equity or political and social acceptability (Schade and Schlag, 2003; Raux and Souche, 2004). Yet economic efficiency remains a precondition in the justification of such schemes. In order to help the decision-maker, costbenefit analyses are performed in order to determine whether this kind of policy, when implemented in a specific area, increases the welfare or not.

Based upon the assessment of the two congestion charging schemes of London and Stockholm, this paper seeks to identify main lessons and research issues at stake when performing a cost-benefit analysis (CBA) on congestion charging.

As it will be shown in the second section, travel time savings form the greatest part of benefits of congestion pricing scheme and this is why the paper will mainly focus on this specific component of benefits. However the reality of travel time savings is subject to criticism and their relevance for cost-benefit analysis of congestion-pricing schemes must first of all be assessed: we argue in this section that these savings are a conservative value of surplus gained from improvement in speed following from congestion charging.

Since travel time savings play a so important role in the assessment of road pricing schemes it seems worth to evaluate the robustness of their computation. The third section implements a simulation model in order to test the sensitivity of time savings to various parameters in the London and Stockholm case studies. It is shown that this sensitivity is indeed very high.

Another growing issue in the literature relates to travel time reliability which is likely to become more important when compared to travel time savings. The fourth section reviews estimates and recent empirical and theoretical work on this topic.

Finally indirect effects, or wider economic benefits (Vickerman, 2007), stemming from transport schemes focus now more and more attention to them. They include effects which are beyond conventional CBA (which incorporates environmental and other direct external costs), such as economic activity, labour or property markets and public funds scarcity. According to the literature these effects can be quite large. These effects are briefly reviewed in the fifth section, along with a simulation exercise regarding the impact of costs of public funds, which we show may be greatly significant. 


\section{THE ISSUE OF TIME SAVINGS IN COST-BENEFIT ANALYSIS}

The London and Stockholm congestion charging schemes are well known and are described in detail elsewhere (see for instance Leape, 2006, for London; and Eliasson, 2008, for Stockholm). Table 1 below shows a summary of cost-benefit analysis for these two schemes. Differences may appear when compared with the above references (for instance because of the inclusion of bus extensions in the Stockholm case) but we will not enter this debate here and concentrate on issues relating to travel time savings and reliability.

Table 1: Summary of cost-benefit analysis for London and Stockholm

\begin{tabular}{lrr}
\hline Summary (€ million per year) & $\begin{array}{r}\text { London } \\
(5 £ \text { charge })\end{array}$ & Stockholm \\
\hline \multicolumn{1}{c}{ Benefits } & 284 & 55 \\
\hline Car users travel time savings & 39 & 8 \\
\hline Car users reliability benefits & 62 & 20 \\
\hline Bus passengers (time savings and reliability) & 25 & 22 \\
\hline Society (accidents and environment) & 410 & 105 \\
\hline Total Costs & & -28 \\
\hline \multicolumn{1}{c}{$\quad-194$} & -60 \\
\hline Charging costs (amortization +operation) & -26 & -1 \\
\hline Additional buses & -29 & 0 \\
\hline Deterred trips (car users) & -32 & -89 \\
\hline Car users compliance costs & -281 & \\
\hline Total & & \\
\hline
\end{tabular}

Sources: Tfl (2007) for London, Transek (2006) for Stockholm and authors' calculation (Currency equivalence is set at $€ 1.45$ for 11 , in 2005, and $€ 0.10512$ for 1 SEK).

Indeed the examination of this table confirms that travel time savings are at the core of costbenefit analysis, for assessing whether transport infrastructure projects or policy measures like road pricing schemes. It shows that, in the London case, car and bus users time savings and reliability benefits amount to $93 \%$ of total benefit ( $79 \%$ for the sole car users time savings). In the Stockholm case these figures are respectively $79 \%$ and $60 \%$.

Remind that in CBA travel time savings are monetised as the sum of two components. The first component is equal to the time gains of those who do not change travel multiplied by the marginal value of travel time (MVOTT). The second one is equal to half the time gains of the new users of the infrastructure (after scheme implementation, i.e. the "induced traffic") multiplied by the MVOTT. This is the usual "rule-of-half". However, in the case of congestion charging induced traffic is not considered to occur since traffic is actually reduced.

Much criticism has been put on the reality of time savings, for instance by Metz (2008) who denounces the "myth" of travel time savings. The argumentation may be summed up as follows. Empirical observations support the hypothesis of individual constant travel time and trip number in the long run. Speed improvements would yield a transient (short-term) situation of travel times reduction but a long term situation where transport users transform the benefit of speed increase into further travel, thus maintaining a constant (daily or yearly) travel time. The increase of travel, the so-called "induced" traffic, would not be higher 
frequency of existing travel but rather access to new destinations. This increased traffic involves more accidents and more harmful atmospheric emissions, thus offsetting the initial environmental benefits. Accordingly cost-benefit analysis (CBA) should consider the value of access to new destinations in lieu of travel time savings. Moreover, according to this criticism, the value of travel time savings would not provide a conservative approximate of the value of access to new destinations, since trips have also an intrinsic utility (e.g. the pleasure of travel or the opportunity of performing parallel tasks such as work while travelling in public transport): the overall surplus should consider both time savings and loss of intrinsic utility for some trips.

A different view from this criticism may be defended. Time devoted to travel generally results in a disutility since this time may be used to perform other activities generally not compatible with travel. Time saved in travel after scheme implementation can be capitalized on by the traveller into two components: the first is time used in activities other than travelling and the second is supplementary travel performed to same destinations as previously or to new destinations. These two components reflect a surplus for the travellers and they can be estimated indirectly by the initial time savings transformed into monetary benefits thanks to the values of time empirically measured.

However since there may be an intrinsic utility in travelling, which could be lost while travel time is reduced, the point here is whether this intrinsic utility is higher or lower than the disutility of travel (in absolute terms). There are obvious cases where this intrinsic utility is higher than the disutility of travel: consider for instance strolling trips, e.g. whether by walking or driving, or even some shopping trips, where the utility of destination merges with the intrinsic utility of the trip. In these cases empirical values of time should demonstrate null or negative figures. This refers to "undirected travel", that is to say when travel is the activity that is demanded (Mokhtarian and Salomon, 2001).

Another case where intrinsic utility of travel may be high when compared with its disutility is when travelling by public transport (i.e. with no need to pay attention to vehicle operation), especially in non crowded situations: activities such as relaxing, reading or working may be performed, so making this a priori "empty" time as being used "productively" (Lyons and Urry, 2005). Even in some cases (perhaps anecdotal but empirically observed by the authors) some (research) managers may take the train solely in order to get some working time for themselves, freed from the pressure of the office: this is a case of "ultra-productive" travel time as identified by Lyons and Urry. Regarding travelling by car as a driver, the potential use of travel time for other activities is more limited since physical and mental attention is required for the operation of the car.

When it comes to the congestion charging schemes studied here we can consider that the intrinsic utility of trips is much limited. Time savings are computed on car travel, where the possibility of performing parallel activities while driving is much limited by the additional stress of driving in congested conditions. The pleasure of travel may also be considered very limited, especially concerning commuting or business trips. In other words the intrinsic utility of this kind of trips may be neglected.

The other issue regards potential induced traffic and its incidence on environment and accidents. In the case of London, benefits from reduction in accidents and harmful atmospheric emissions represent only $6 \%$ of the overall benefits (see Table 1). Moreover, according to TfL (2005) no significant increase occurred in the traffic surrounding the charged area. So, even if additional travel may be performed as a result of time saved from the new traffic conditions, its incidence on environment may be neglected compared with the amount of benefits coming from time savings estimation. 
The Stockholm case is different from this point of view since benefits from reduction in accidents and harmful atmospheric emissions represent a noticeable part of the overall benefits, i.e. $22 \%$ (see Table 1). Besides, an increase in traffic has been observed on a bypass around the charged zone, recently opened at the time of the trial: according to Transek (2006) this increase in traffic should not be attributed to an effect of congestion charging but rather to the usual progressive increase of traffic in newly opened infrastructures. Yet one cannot exclude that in the long term induced traffic would have consequences such as wiping out the short-term environmental and accidents benefits as currently estimated.

Last, one should consider the simplification made when considering "official" (and average) values of time. This simplification is a concern if one is interested in calibrating a behavioural model or in estimating real potential income from infrastructure pricing for a public-private partnership. Indeed empirical evidence shows that because of the heterogeneity of drivers, value of travel time should rather be represented as a distribution (Hensher and Goodwin, 2004). However we are interested here in the appraisal of congestion pricing scheme within the conventional CBA framework which until now makes use of "official" average value of time, whose values represent the choices of the society.

Both in London and Stockholm cases distinction is made between business trips and private trips (of which most are commuting trips). However, regarding especially private trips, individuals have different values of time reflecting heterogeneity for instance in wages for workers. Drivers who leave the road have lower values of time, so the ex post average value of time will be higher than the ex ante one. Thus the computation of monetary benefits from time savings with an "official" value of time which remains fixed represents an underestimation of the surplus for drivers remaining on the road.

Overall our conclusion is that first, time savings resulting from congestion charging may be wiped out in the longer term by induced traffic (or by a subsequent reduction of road capacity as in the London case; see TfL, 2008). But second, these time savings can reasonably be taken as a conservative estimate (in fact an underestimation) of the benefits obtained by access to new destinations for transport users. This second point rejoins the conclusions of Mackie (2008) and Van Wee and Rietveld (2008).

Since these time savings play a crucial role in the CBA, their assessment needs some scrutiny.

\section{Which scope for time savings? The example of London}

In the London case the overall time savings of car users are estimated by TfL (2007) to be about $€ 280$ million per year. As indicated by TfL these savings may be broken down according to areas where travel occurs. TfL distinguishes the "Charged area", the "Inner area" and the "Outer area". 
Table 2: Breakdown of time gains per area in London

\begin{tabular}{llrrrr}
\hline & \multicolumn{1}{c}{ unit } & Charged area & Inner area & Outer area & Total \\
\hline Post-charge veh km & 1000 per day & 1,276 & 14,722 & 32,708 & 48,706 \\
\hline Time saved per veh km & minutes & 0.59 & 0.06 & 0.01 & \\
\hline Value of time vehicle & $€$ per hour & 44 & 32 & 25 & \\
\hline Time gains & million $€$ per year & 135 & 117 & 37 & 290 \\
\hline
\end{tabular}

(Source: Tfl; 2007, appendix and authors calculation. Charge is applied from Monday to Friday, excluding bank holidays, i.e. approximately 255 days per year)

As shown in Table 2 the saving per kilometre amounts to 0.06 minute in the Inner Area and 0.01 minute in the Outer Area. Weighted by the corresponding traffic volumes (respectively 14,722 and 32,708 thousands vehicle-kilometre), these savings yield 14,245 hours saved per day in the Inner area (more than the 11,953 hours saved in the Charged area) and 5,812 hours saved per day in the Outer area. Combined with the values of travel time in these areas, this gives added monetised time savings of respectively $€ 117$ million and $€ 37$ million per year: overall this doubles the time savings computed on the sole Charged area ( $€ 135$ million).

When it comes to the perspective of user behaviour, the savings of 0.06 minute per kilometre in the Inner area and 0.01 minute per kilometre in the Outer area look very low when compared to the significant level of saving in the Charged Area, i.e. 0.59 minute per kilometre. For instance, for a 10 kilometres trip these savings of 0.06 minute and 0.01 minute per vehicle-kilometre represent respectively 36 seconds and 6 seconds: this should be compared to the total duration of the trip which is about 30 minutes according to TfL.

Welch and Williams (1997) offer an in-depth analysis of the impact of small time savings on transport investments benefits, and provide sensitivity tests. They note that CBA is dominated in a large number of transport schemes by small travel time savings of less than five minutes. They recommend that particular scrutiny should be given to these savings under five minutes. For Mackie et al (2001) there is no justification for not assigning a constant unit value per minute of time saving regardless of the size of the time savings. In their review of evidence given by previous studies, Mackie et al (2003) recognise that a lower unit value of time is attributed to small time savings in an empirical study on travel behaviour but they attribute this effect to the stated preference (SP)-based nature of the investigation. They conclude their meta-analysis of studies of valuation of travel time savings (VTTS) by rejecting the differentiation of values of travel time savings according to the size of time savings. However, they also recognise that the VTTS varies according to the trip distance but this raises and issue of consistency with microeconomic theory. According to the authors, further work is needed on the marginal utility of time and cost with respect to the levels of trip time and cost before including variable VTTS in evaluation. For instance, Small et al (2005) show with a mix of RP and SP studies on tolled express lanes in California, and models allowing for unobserved heterogeneity, that VTTS vary with trip length and that those with very long commutes have lower VTTS. According to the authors, one explanation could be that long distance commuters are those who cannot afford for housing near their job place, and have lower income and thus lower VTTS.

Nevertheless, while the use of a constant unit value of time should be recognised in consideration for consistency with $\mathrm{CBA}$, we are considering here average journey time 
savings of 6 or 36 seconds. The low level of these figures casts doubt on the statistical confidence of the modelled values and questions the relevance of including such benefit in the evaluation.

This is why in order to obtain a conservative value of the benefits of time savings following from the reduction in traffic, the scope of savings to take into account in the London case should stick to those measured within the charged area, that is to say $€ 135$ millions as given by TfL.

\section{THE SENSITIVITY OF TIME SAVINGS TO VARIOUS PARAMETERS}

Since time savings bear the greatest share in benefits of a transport policy, it is relevant to ask to what extent these time savings vary according to different sources of errors or uncertainties. We focus the analysis on car user time savings, leaving aside bus user time savings. Indeed actual bus speed and frequency of service are usually accurately monitored and reported, and user time savings are less prone to measurement errors. On the opposite car traffic volume and speed are estimated through a combination of traffic counts, floating vehicles and modelling techniques, which increases the probability and scope of errors.

In order to evaluate these errors we have implemented our own model of simulation of congestion. We use a static congestion model which, given the available data, seems the most relevant tool. Indeed the bottleneck model (Vickrey, 1963, 1969; Arnott et al, 1993) would be more relevant from a theoretical point of view: however, apart from the issue of availability of detailed data, as far as we are aware there is no implementation of this model at a network level.

This approach could be considered too crude if the objective was to evaluate the actual level of aggregate time savings in both case studies. However the aim here is rather to evaluate the sensitivity of time savings to errors of input parameters. As shown below we use the optimal pricing scheme with a static model as a benchmark against which the sensitivity tests are performed.

We first present the methodology of implementation, which is then successively applied with sensitivity tests in the London and the Stockholm cases.

\subsection{The static short run congestion model}

Figure 1 shows the basic model of static short run congestion with traffic volume on $\mathrm{X}$-axis and cost on Y-axis (see for instance Button, 2004). ASC is the average social cost curve, which is obtained by reversing the speed-flow curve (Walters, 1961; Morrison, 1986). An additional user of the road is considering only the time and vehicle operation costs he has to bear: with many users this time cost equates to the average time cost of all current users. Thus the $A S C$ confounds with the marginal private cost $(M P C)$ of the road user. The marginal social cost $(M S C)$ curve represents the extra cost that the additional user places on the existing traffic flow. The difference between the $A S C$ and the $M S C$ curves at any level of traffic flow equates with the marginal congestion cost, i.e. the externality of congestion.

The demand curve is figured straight for the sake of simplicity and represents the marginal willingness to pay of road users for taking the road. At the equilibrium $B$ between demand and $M P C$ (or $A S C$ ), without any implementation of congestion charging, the volume traffic is 
$Q_{c}$. This situation represents a social loss since drivers enjoy a private benefit of $Q_{c} B$ but incur a social cost of $Q_{c} A$. Thus $Q_{c}$ is an excess traffic from a social point of view which should be reduced to the optimal traffic volume $Q_{0}$ at which level private benefit of the additional user equals the social cost he/she incurs. $A D B$ is the "deadweight loss" coming from congestion.

Congestion charging aims at internalising the externality of congestion, by making drivers to pay a charge, which is optimal at level $r$ yielding optimal traffic volume $Q_{0}$. However in practical implementations studied in this paper, the actual charge $p$ that is implemented may be different from the optimal one: it yields the actual level of traffic $Q_{0}^{\prime}$ after scheme implementation and $A^{\prime} B^{\prime} B A$ is the actual time savings gained from the implementation of charge $p . B^{\prime} C^{\prime} B$ is the loss of evicted users.

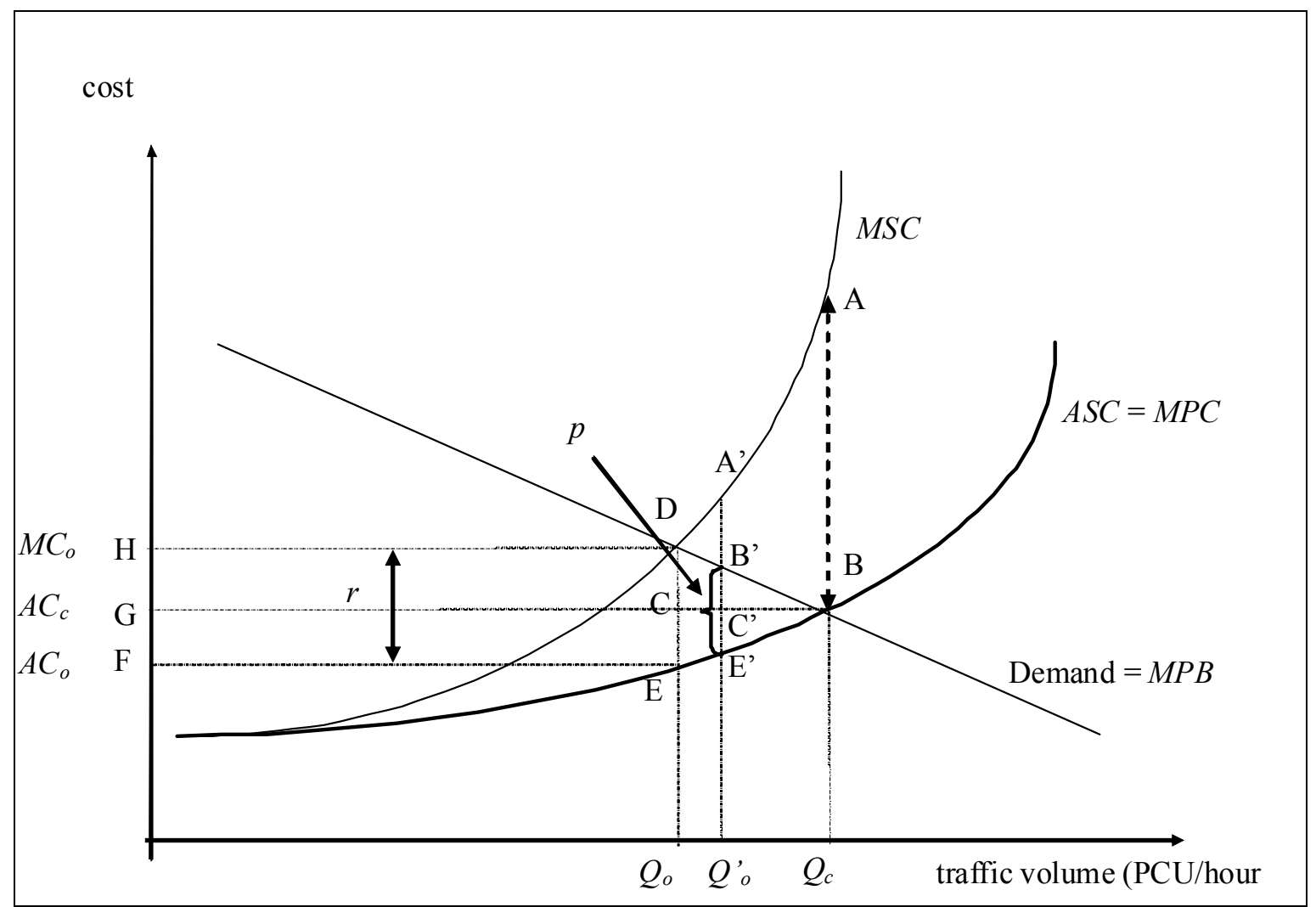

(source: adapted from Button, 2004)

\section{Figure 1: The static short run congestion model}

The core of congestion charging benefit lies in the time savings $A^{\prime} B^{\prime} B A$. In order to estimate these time savings and to perform some sensitivity analyses we have implemented this model on a data sheet.

For this implementation we need to estimate the function of speed according to traffic level, the average charge $(p)$ and the value of time for car trips.

For the speed function we use a common specification (as in Prudhomme and Bocarejo, 2005)

$v(q)=v_{0}-b q$ 
where $v_{0}$ is the free-flow speed, $q$ the traffic and $b$ a parameter to estimate. This function describes the technical capacity of the road network. It is calibrated from aggregate traffic and average speed before and after scheme implementation.

Average charge per vehicle-kilometre $p$ is computed from annual revenues and traffic volume (in vehicle-kilometres).

Average social cost $A S C$ is assumed to vary only with the trip duration, thus with the traffic speed. Marginal social cost $M S C$ is obtained by derivation of average cost. Thus the cost functions can easily be calibrated. The demand function can also be calibrated from the knowledge of speed function (see above) and both average costs and traffic level before and after scheme implementation (following the methodology described in Prudhomme and Bocarejo, 2005): thus the slope of the demand function (assumed to be a straight line) varies according to value of time, speed and traffic volume before and after scheme implementation, and average charge.

Various sensitivity tests are performed, as shown below, to variations of traffic volume and average speed measured before and after. It should be noted that for each change of input parameter the model recalibrates the speed-flow relationship (slope $b$ in equation (1)) and thus the average and marginal social costs, to obtain finally the new figure for monetised travel time savings $A$ ' $B$ ' $B A$. Regarding variations of the "official" value of time this only changes the monetised result, not the total travel time savings.

\subsection{Implementation in the London case and sensitivity of time savings}

\section{Implementation of the model in the London case}

Data for calibrating speed function are available in TfL (2007): these include before and after aggregate traffic volumes (respectively 1,531 and 1,276 thousands of veh-km), average speeds (resp. 14.10 and $16.40 \mathrm{~km} / \mathrm{h}$ ) and average charge per veh-km $0.85 €$. The calibration of equation (1) gives a slope $b$ of 0.009 . The value of time is given by TfL (2007): the average figure is 42 pence per minute per person in the Central Area that is to say $37 €$ per person per hour (with a currency equivalence of $€ 1.45$ for $£ 1$ ).

From this computation we obtain monetised time savings of $€ 133$ million per year in the Charged Area which can be compared to TfL estimates of $€ 135$ million in the same area. This gives at least a partial validation of our model implementation.

\section{Sensitivity in the London case}

Equipped with this model, we can use it to assess the sensitivity of monetised time savings to various parameters: indeed these parameters influence both supply and demand curves as described above (assuming the same relative error in the measurement of these parameters, i.e. plus/minus $10 \%$ ).

The figures of impacts in Table 3 show that the parameter that influences the most the amount of time savings is the speed measured before or after: the order of magnitude of time savings variation in response to variations of $\pm 10 \%$ of speed is about 80 to $100 \%$ of time savings. In comparison the sensitivity to errors of the same kind in the value of travel time or traffic levels is almost negligible. 
Table 3: Sensitivity of monetised time savings to various parameters in the London case

\begin{tabular}{lrrr}
\hline & Reference & variation & $\begin{array}{r}\text { Impact on time } \\
\text { savings }\end{array}$ \\
\hline individual value of time $(€ / \mathrm{h})$ & 37.00 & $+10 \%$ & $12 \%$ \\
& & $-10 \%$ & $-12 \%$ \\
\hline average speed before $(\mathrm{km} / \mathrm{h})$ & 14.10 & $+10 \%$ & $-79 \%$ \\
& & $-10 \%$ & $+102 \%$ \\
\hline average speed after $(\mathrm{km} / \mathrm{h})$ & 16.40 & $+10 \%$ & $+72 \%$ \\
& & $-10 \%$ & $-83 \%$ \\
\hline traffic before $(000$ veh-km) & 1531 & $+10 \%$ & $-5 \%$ \\
& & $-10 \%$ & $+5 \%$ \\
\hline traffic after $(000$ veh-km) & 1276 & $+10 \%$ & $+16 \%$ \\
& & $-10 \%$ & $-18 \%$ \\
\hline
\end{tabular}

\subsection{Implementation in the Stockholm case and sensitivity of time savings}

\section{Implementation of the model in the Stockholm case}

In the Stockholm case we have implemented the same model but with a modification in order to take into account the impact separately on traffic on radial access routes to the charging area on the one hand, and on traffic within this area (which is not charged contrary to London) on the other hand. Thus the average cost $A S C$ is broken down into two components, and the speed, demand and supply functions are calibrated separately for radial access to and traffic within the charged area.

Our data are taken from Prud'homme and Kopp (2010) who based their analysis on data from the Stockholm city for traffic entering and leaving the city center, and from a 2004 Transport Survey for traffic having both their origin and destination within the city center. The authors assume that traffic within the city center remains constant since it doesn't pay the toll. The figures for traffic entering and leaving the city center before and after scheme implementation are respectively 410 and 328 thousands of veh-km, and for central traffic 103 thousands of veh-km (this last adds to entering traffic to form the overall traffic within the cordon).

Average speeds on radial routes before and after scheme implementation are respectively 49.87 and $51.05 \mathrm{~km} / \mathrm{h}$; the figures for speeds within the center are resp. 23.72 and $26.19 \mathrm{~km} / \mathrm{h}$. The former are computed from thousands of measurements on traffic densities at various points in both directions, the latter by the means of floating car speed data (see Prud'homme and Kopp, 2010). The calibration of equation (1) gives a slope $b$ of 0.04 for central traffic and 0.02 for radial traffic. These figures are two to four times higher than in the London case (0.009). This is to be related to central Stockholm speeds about two times higher than the London ones, which indicate a fairly low level of congestion in Stockholm when compared with London.

The average charge per veh-km is 9.7 SEK (1.02 $€)$. The average value of time in Stockholm is 122 SEK per hour and vehicle, thus with an average load factor of 1.25 , a personal value of time of 97.6 SEK per hour $(10.3 €)$.

From these figures we obtain monetised time savings of $€ 18$ million per year: this is one third of the estimate of Transek which amounts to $€ 55$ million. 
In the estimation made by TRANSEK (2006), the calculation of traffic flows and travel times is based on a mix of statistical method (in the charged area) and model calculations elsewhere (Stockholm's Stad, 2006). Indeed the statistical method needs a great input of data. Traffic flows are measured on a large number of roads in 15 minutes time intervals while for other roads a "matrix calibration" technique is used. For travel times, cameras, floating car surveys, speed detectors and model calculations are used. According to Eliasson (2009) this explains the difference in estimations of time savings, since Prud'homme and Kopp basically use point speed measurements from traffic counts detectors (and the speed is dependent on the location of the detector, e.g. if it is near a junction where traffic is queuing or not) in order to estimate the aggregate speed and aggregate traffic before and after scheme implementation.

It is not possible here to settle the question between these two methods of measurement which both involve their own batch of errors. However our main interest is to analyse the sensitivity of the results in (monetised) time savings to measurement errors of various parameters inputted in our simulation model. This is why we will again use our model to test this sensitivity in the Stockholm case. One should also note that the variations in traffic and speed that are tested roughly include the potential differences in measurement between the TRANSEK and Prud'homme and Kopp studies.

\section{Sensitivity in the Stockholm case}

Here again as in the London case we test the impact of relative errors of plus/minus $10 \%$ in the input parameters. This level of variation of $10 \%$ may be justified by the $95 \%$ confidence intervals shown in traffic measurements in the inner city (Stockholm's Stad, 2006; p. 41).

Table 4: Sensitivity of monetised time savings to various parameters in the Stockholm case

\begin{tabular}{lrrr}
\hline & Reference & variation & Impact on time savings \\
\hline individual value of time $(€ / \mathrm{h})$ & 10.3 & $+10 \%$ & $14 \%$ \\
& & $-10 \%$ & $-14 \%$ \\
\hline average radial speed before $(\mathrm{km} / \mathrm{h})$ & 49.48 & $+10 \%$ & $-56 \%$ \\
& & $-10 \%$ & $71 \%$ \\
\hline average radial speed after $(\mathrm{km} / \mathrm{h})$ & 51.05 & $+10 \%$ & $56 \%$ \\
& & $-10 \%$ & $-66 \%$ \\
\hline average central speed before $(\mathrm{km} / \mathrm{h})$ & 22.89 & $+10 \%$ & $-88 \%$ \\
& & $-10 \%$ & $113 \%$ \\
\hline average central speed after $(\mathrm{km} / \mathrm{h})$ & 26.19 & $+10 \%$ & $76 \%$ \\
& & $-10 \%$ & $-94 \%$ \\
\hline radial traffic before $(000 \mathrm{veh}-\mathrm{km})$ & 410 & $+10 \%$ & $-7 \%$ \\
& & $-10 \%$ & $21 \%$ \\
\hline radial traffic after $(000$ veh-km) & 328 & $+10 \%$ & $13 \%$ \\
& & $-10 \%$ & $-5 \%$ \\
\hline central traffic before $(000 \mathrm{veh}-\mathrm{km})$ & 103 & $+10 \%$ & $-12 \%$ \\
& & $-10 \%$ & $-4 \%$ \\
\hline central traffic after $(000 \mathrm{veh}-\mathrm{km})$ & 103 & $+10 \%$ & $3 \%$ \\
& & $-10 \%$ & $-3 \%$ \\
\hline
\end{tabular}

Regarding the sensitivity of time savings to speed, the figures in the Stockholm case (see Table 4) are of the same order of magnitude as in the London case. In Stockholm time savings show a very high sensitivity to speed measured on radial access (about $60-70 \%$ of variation in 
response to a $\pm 10 \%$ of speed variation) and even more in the central area, i.e. inside the cordon (about $80-100 \%$ of variation in response to a $\pm 10 \%$ of speed variation).

This sensitivity is roughly the same in Stockholm as in London, when it comes to variation of traffic before and after, whether for radial traffic or for central traffic (the part of traffic volume which remains within the cordon). This similarity is obtained despite significant differences in congestion levels (see the difference in speeds measured). Recall from above that the slope of speed to traffic volume is two to four times higher than in the London case.

To conclude on this sensitivity issue what do these results tell us? The estimation of time savings is extremely sensitive to the measurement of speeds before and after scheme implementation: this result is obtained in two contexts with very different level of congestion and hence speed-flow relationships. This underlines the need to accurately measure speeds on various links but also to recognise an inherent uncertainty in the range of time savings. This supports the idea of intervals of magnitude for CBA components rather than unique figures. Moreover the monetary value of travel time looks far less critical in view of this sensitivity results.

However these benefits in time savings do not include the gains from improved reliability in journey times, an issue that is addressed hereafter.

\section{THE RELIABILITY OF TRAVEL TIME}

What is the extent of reliability gains? Are they worth computing accurately? TfL (2007) gives an estimation of reliability gains for car users, based on a study which calculated link speeds and estimated the reliability of total journey time by highway modes: for this, the standard deviation of travel time is estimated from a relationship between current time and free-flow time. The reliability benefit on each link was estimated as 0.79 times the reduction in the standard deviation of the link time (which is approximately the practice recommended in the UK for the "reliability ratio": see WebTAG Unit 3.5.7). From this, reliability savings are estimated to be an added $30 \%$ of travel time savings in the charging zone and zero elsewhere.

Reliability gains accrue also to bus passengers since they benefit from a reduction in excess waiting times which is estimated at 30\% inside the charged area (TfL, 2005). According to TfL this gives a reliability gain for bus passengers equivalent to nearly half their time savings.

In the Stockholm case a significant reduction in travel time unpredictability also occurred (Stockholm's Stad, 2006): travel time variability measured as the difference in journey times between the best (10th percentile) and the worst days $\left(90^{\text {th }}\right.$ percentile) was at least halved on morning peak on inner approach roads toward the city centre, and at least divided by five on afternoon/evening peak on the opposite direction. In Sweden the recommended reliability ratio is 0.9 , like in the UK. Overall the benefits from improvement in travel time reliability is estimated at $15 \%$ of total travel time savings.

These amounts of reliability gains when compared to time savings are not abnormal. Brownstone and Small (2005) estimate that in the case of Californian toll motorways the value of the reliability of journey time is in the range of 95 to $140 \%$ of the median value of time. They conclude that two-thirds of the value of the service provided by a toll motorway in relation to a toll-free motorway is due to journey time and one third to reliability. Bates et al 
(2001) provide a detailed discussion of the valuation of reliability both on theoretical and empirical aspects.

Van Lint et al (2008) underline that there exist several definitions of reliability beyond the common use of indicators of the variance of travel time distribution. They observe heavily skewed distributions in empirical data and argue in favour of indicators that should take into account not only the variance but also the skew of travel time distribution.

These calculations which relate the mean and variance of travel times, and reflect current practice in appraisal, are based on empirical approaches. However a theoretically sound alternative approach may be used.

The standard behavioural hypothesis is that the transport user, considering a fixed destination as is the case for commuting, attempts to minimize his/her generalized travel cost across the modes, which combines the pecuniary travel cost, the travel time cost and the cost of late or early arrival: this is known in the literature as the "scheduling theory" introduced by Small (1982) on the grounds of the Vickrey's bottleneck model (1969).

De Palma and Fontan (2000) have measured the parameters of the scheduling model for home-to-work trips in the Paris Region, and arrived at $€ 12.96$ per hour for travel time (which is roughly consistent with the recommended value of time in France, see CGP, 2001), €8.61 per hour for early arrival and $€ 30.22$ per hour for late arrival, i.e. more than twice the value of travel time.

Furthermore, on the basis of their SP survey on rail travel, Bates et al (2001) show that punctuality is highly valued by travellers and suggest that in the case of public transport where departure times are discrete, there would be a disutility of unreliability distinct from that of scheduling delay. Moreover, they indicate plausible values for the reliability ratio in car travel of 1.3 which are substantially higher than those used in current CBA practice (see above).

More recently Fosgerau and Karlström (2010) have shown that under some assumptions the scheduling model can be unified with models that include the standard deviation of duration directly as an argument in the cost or utility function.

These various works show that this is an active research field, aiming at building a consensus on valuing travel time reliability (or rather travel time variability). Higher levels of reliability ratio would imply a much higher share given to travel time reliability improvement when compared to mean travel time reduction. More empirical work is needed in measuring the parameters of the scheduling model with whether stated or revealed preferences surveys.

\section{INDIRECT EFFECTS}

These effects, also designated as wider economic benefits, are numerous. Vickerman (2007) offers an overview and a discussion on the methodology of measurement and modelling of these effects, which in fact can be positive or negative. In this section we briefly refer to some work about the agglomeration benefits and on employment. We also review scarce empirical evidence about the effects on retail activity. Finally we provide insights on an issue not often addressed, that of the scarcity of public funds, with a simulation of its impact in congestion pricing schemes. 
Regarding the effects on agglomeration benefits and productivity, Venables (2007) argues that transport improvements may impact the city size and hence the productivity of workers: according to this author the econometric estimates suggest a large effect. Pilegaard and Fosgerau (2008) also address the issue of labour market. They show that when there are imperfections in search unemployment, a transport infrastructure improvement may have significant welfare positive effects, something that is not currently included in conventional CBA. The issue is whether these welfare improvements may apply to congestion pricing schemes.

Regarding the economic activity empirical studies have been performed on both London and Stockholm case studies and the conclusions are divided. On the one hand, in the London case, Quddus et al (2007) show evidence of a drop in sales at one of the biggest stores within the charged area, attributable to the congestion charging scheme. On the other hand, in the Stockholm case Daunfeldt et al (2009) show that the road pricing trial had no negative affect on retail revenue in shopping malls within the cordon.

\section{The issue of public funds}

Modern CBA adds now to the analysis of real effects of investments the financial consequences from the point of view of public funds. The marginal cost of public funds (MCPF) is defined as "the direct tax burden plus the marginal welfare cost produced in acquiring the tax revenue" (Browning, 1976). One example of this welfare cost is when VAT reduces consumption or when taxes on work income distort the work supply decisions of workers.

MCPF seems to be ignored in the UK appraisal current practice (at least in TfL, 2007), but it is taken into account in Sweden (it is set at 1.3, that is to say each incremental unit of money collected by tax costs 1.3 unit to the society, or 0.3 unit in welfare cost).

In Sweden, appraisal adds the opportunity cost of capital (the rate of return for public funds is set at $23 \%$ ). Confusion occurs sometimes in the literature between these two kinds of costs. The MCPF refers to the distortion effect of the tax levy while the opportunity cost refers to the value in the best alternative use of these funds.

However, Jansson (2008) argues that the MCPF should not be taken into account. Indeed the standard CBA of transport investment or scheme assumes only marginal effects on other markets than the transport one, so that these effects should be ignored. This assumption would not be valid for a congestion charging scheme since it affects the supply cost and concentration of labour force in the city center (see above).

Table 5 below illustrates the impact of the costs of public funds on the public accounts in the case of London and Stockholm, with a MCPF of 1.3 and an opportunity rate of $15 \%$ (in order to ensure a common level of comparison between case studies).

Toll revenues are considered as having no distorting effect on consumption and hence yield a gain in welfare (rate of 0.3 for a MCPF of 1.3) when compared to conventional taxation revenues. Additional revenues from public transport increased use also yield a gain in welfare with respect to alternative financing (e.g. subsidies) by taxation. On the opposite an increase of public expenses (here the investment and the operation of congestion charging and new buses) or a decrease of current fiscal revenues (such as VAT or fuel excise) are weighed down with the MCPF. Opportunity costs are also applied to public expenses.

We have added the example of Oslo, which is not a "congestion" charging but a simpler "road user" charging scheme which started in 1991. In Oslo there was no objective of reducing 
traffic or the pollution from automobile, but rather to levy new funds in order to finance a package of new infrastructure investments. The charging system is simpler than in London or Stockholm, with basically embarked on-board units and a dialogue with road-side beacons at a few gantries. Thus the costs of charging (operation plus depreciation) amount roughly to $10 \%-12 \%$ of toll revenues.

Table 5: The impact of costs of public funds

\begin{tabular}{lrrr}
\hline \multicolumn{1}{c}{ Public accounts ( $€$ million per year) } & London & Stockholm & Oslo \\
\hline Congestion charge revenues & 312 & 80 & 77 \\
\hline Additional bus revenues & 28 & 19 & -9 \\
\hline Congestion charge costs (operation + depreciation) & -194 & -28 & -60 \\
\hline Additional bus costs (operation + depreciation) & -26 & -6 & 68 \\
\hline Variation of fiscal revenues (excise fuel + VAT) & -55 & 6 & 23 \\
\hline \multicolumn{1}{c}{ Total Public Funds } & 65 & 24 & -3 \\
\hline MCPF Congestion charge revenues & 94 & -8 & \\
\hline MCPF Congestion charge costs & -58 & 6 & \\
\hline MCPF Additional bus revenues & 8 & -18 & -1 \\
\hline MCPF Additional bus costs & -8 & -2 & -4 \\
\hline MCPF Variation of fiscal revenues & -17 & -9 & \\
\hline Opportunity costs Congestion charge expenses & -29 & -11 & 19 \\
\hline Opportunity costs Additional bus expenses & -4 & -5 & 87 \\
\hline Total Cost of Public Funds (MCPF $=1.3)$ & -14 & & 33 \\
\hline Total (MCPF $=1.3)$ & 51 & -10 & 101 \\
\hline
\end{tabular}

Sources: Tfl (2007) for London, Transek (2006) for Stockholm, Norwegian Public Roads Administration (2006) for Oslo, and authors' calculation.

Two main lessons can be drawn from this table. First, the total impact of public funds costs on public accounts is significant in the three cases (compare the "total costs of public funds" item to the "total public funds" item) and may even put the accounts in the red (see Stockholm). Second, the MCPF has a multiplicative effect on the difference between revenues from congestion (or road use) charging and the expenses needed to levy them (compare the two first lines of MCPF in Table 5).

Moreover, if as suggested by the results of Kleven and Kreiner (2006) much higher levels of MCPF than usually considered would occur, then the multiplicative effect of MCPF would have also a greater impact on public accounts. The two last lines in Table 5 show the impact of setting MCPF at 1.5, a value observed in the empirical literature. This highlights particularly the issue of the charging technology which directly impacts the investment and operation costs of the scheme, especially in the case of London. The technology has obvious links with the objectives, the topography, the charge level and the operating hours of the scheme. The MCPF issue highlights also the impact of financing accompanying measures such as additional public transport supply as in the Stockholm case. 


\section{CONCLUSION}

Time savings gained from short-term improvements in speed following from congestion charging implementation provide a conservative estimate (and probably an underestimation) of the scheme benefits. Indeed, even if these time savings may be overcome by induced traffic in the longer term, they represent an indirect estimation of benefits from access to new destinations which are reflected by this induced traffic. However there is a need to be also conservative and cautious when considering very small time savings.

The methodology of measurement of travel time reliability (or variability) is not yet stabilised, but recommended estimates and moreover current empirical work suggest that it may take a growing share of benefits in the near future. Growing preferences toward travel time reliability rather than pure travel time reduction should have implications for transport policy.

The sensitivity tests performed in the London and Stockholm case studies indicate an extreme sensitivity of time savings benefits in both cases to slight errors in the measurement of speed, whether before or after scheme implementation. This common evidence is obtained despite significant differences in the level of congestion between London and Stockholm. This underlines the need to accurately measure this parameter but also to recognise an unavoidable uncertainty: this is in favour of interval values in the CBA balance sheet rather than unique figures. Moreover, the monetary value of travel time looks far less critical in view of this sensitivity results.

Finally the impact of costs of public funds on public accounts is greatly significant. The MCPF has a definite multiplicative effect on the difference between revenues from congestion (or road use) charging and the expenses needed to levy them, this effect being magnified by higher MCPF figures that would be suggested by the relevant literature.

\section{ACKNOWLEDGEMENTS}

This research has benefited from a grant of the Direction for Research and Innovation in the French Department in charge of transport (MEEDM), Grant no. 07MTE042. We thank participants at the Kuhmo-Nectar seminar (Valencia, 8-9 ${ }^{\text {th }}$ July 2010) and the World Conference in Transport Research (Lisbon, 11-15 ${ }^{\text {th }}$ July 2010) for their valuable comments.

\section{REFERENCES}

Arnott, R., de Palma, A. Lindsey, R; 1993. A structural model of peak-period congestion: A traffic bottleneck with elastic demand. The American Economic Review, vol. 83, No 1 (Mar., 1993), 161-179.

Bates, J., Polak J., Jones P., Cook A., 2001. The valuation of reliability for personal travel. Transportation Research Part E 37 (2001) 191-229. 
Brownstone, D., Small, K.A., 2005. Valuing time and reliability: assessing the evidence from road pricing demonstration. Transportation Research A. vol 39, pp. 279-293.

Button, K., 2004. The rationale for road pricing: standard theory and latest advances. Research in Transport Economics, Volume 9, pp. 3-25.

CGP, 2001. Commissariat Général du Plan, Transports: choix des investissements et coût des nuisances. Rapport du groupe présidé par Marcel Boiteux, Paris, La Documentation Française, $325 \mathrm{p}$.

Daunfeldt, S.-O., Rudholm, N., Rämme, U., 2009. Congestion charges and retail revenues: Results from the Stockholm road pricing trial. Transportation Research Part A 43 (2009) 306-309.

De Palma, A. Fontan, C., 2000. Enquête MADDIF: Multimotif adaptée à la dynamique des comportements de déplacements en Ile-de-France. Rapport de recherche pour la DRAST, Paris, $147 \mathrm{p}$.

Eliasson, J., 2008. Lessons from the Stockholm congestion charging trial. Transport Policy, Volume 15, Issue 6, November 2008, Pages 395-404.

Eliasson, J., 2009. A cost-benefit analysis of the Stockholm congestion charging system. Transportation Research Part A, Vol. n43, p.468-480.

Fosgerau, M., Karlström, A., 2010. The value of reliability. Transportation Research Part B 44 (2010) 38-49.

Hensher, D.A., Goodwin, P. 2004. Using values of travel time savings for toll roads: avoiding some common errors. Transport Policy 11 (2004) 171-181.

Jansson, J.O., 2008. Public transport policy for central-city travel in the light of recent experiences of congestion charging. Research in Transport Economics 22 (2008) 179-187.

Kleven, H. J., Kreiner C. T., 2006. The marginal cost of public funds: Hours of work versus labor force participation. Journal of Public Economics 90 (2006) 1955-1973.

Leape, J., 2006. The London congestion charge. Journal of Economic Perspectives, Vol 20, $\mathrm{N}^{\circ}$, Fall 2006, pp. 157-176.

Lyons, G., Urry, J., 2005. Travel time use in the information age. Transportation Research Part A, 39(2005) 257-276.

Mackie, P., 2005. The London congestion charge: a tentative economic appraisal. A comment on the paper by Prud'Homme and Bocarejo, Transport Policy, 12, 288-290.

Mackie, P., 2008. Who knows where the time goes? A response to David Metz. Transport Reviews, 28: 6, 692-694.

Mackie, P.J., Jara-Diaz, S., Fowkes, A.S., 2001. The value of travel time savings in evaluation. Transportation Research Part E 37 (2001) 91-106.

Mackie, P.J., Wardman, M., Fowkes, A.S., Whelan, G., Nellthorp, J., Bates, J., 2003. Values of Travel Time Savings in the UK. Report for the Department of Transport. Institute of Transport Studies, University of Leeds.

Metz, D., 2008. The Myth of Travel Time Saving. Transport Reviews, 28:3, 321-336.

Mokhtarian, P., Salomon, I., 2001. How derived is the demand for travel? Some conceptual and measurement considerations. Transportation Research Part A, 35(2001) 695-719.

Morrison, S., 1986. A survey of road pricing. Transportation Research Part A, 20, 87-97. 
Norwegian Public Roads Administration, 2006. Website of the Curaçao project (November 2009) http://www.curacaoproject.eu/

Pilegaard, N., Fosgerau, M., 2008. Cost Benefit Analysis of a Transport Improvement in the Case of Search Unemployment. Journal of Transport Economics and Policy, Volume 42, Part 1, January 2008, pp. 23-42.

Prud'Homme, R., Bocarejo, J-P., 2005, The London congestion charge : a tentative economic appraisal, Transport Policy, 1-9.

Prud'Homme, R., Kopp, P., 2010, The economics of urban tolls: lessons from the Stockholm case. International Journal of Transport Economics, Anno XXXVII, 2, 2010, 195-222.

Quddus, M., Bell, M.G.H., Schmöcker, J.D., Fonzone, A., 2007. The impact of the congestion charge on the retail business in London: An econometric analysis. Transport Policy 14 (2007) 433-444.

Raux, C., Souche, S., 2004. The acceptability of urban road pricing: A theoretical analysis applied to experience in Lyon. Journal of Transport Economics and Policy. Vol 38, Part 2, May 2004, pp. 191-216.

Raux, C; 2005. Comments on "The London congestion charge: a tentative economic appraisal" (Prud'homme and Bocarejo, 2005). Transport Policy, 12 (2005) 368-371.

Santos, G., Fraser, G., 2006. Road Pricing: Lessons from London. Economic Policy. 21(46): 264-310

Schade, J., Schlag, B. (Eds.), 2003. Acceptability of transport pricing strategies. Elsevier.

Small, K.A. 1982. The scheduling of consumer activities: work trips. American Economic Review 72, 469-479.

Small, K.A., Winston, C., Yan J., 2005. Uncovering the Distribution of Motorists' Preferences for Travel Time and Reliability. Econometrica, Volume 73, Issue 4, 1367 - 1382.

Stockholm's Stad, 2006, Evaluation of the effects of the Stockholm trial on road traffic, 81p.

TRANSEK, 2006, Cost Benefit analysis of the Stockholm Trial, 2006:31, 83p.

Transport for London, 2004. Congestion Charging Central London. Impacts Monitoring Second Annual Report, April 2004, 120 p.

Transport for London, 2005. Central London Congestion Charging Scheme. Impacts Monitoring. Summary Review. January 2005. 53 p.

Transport for London, 2007. Central London Congestion Charging Scheme: ex-post evaluation of the quantified impacts of the original scheme. 29 June 2007, 29 p.

Transport for London, 2008. Congestion Charging Central London. Impacts Monitoring Sixth Annual Report, July 2008, 227 p.

Van Lint, J.W.C., Van Zuylen, H. J., Tu, H., 2008. Travel time unreliability on freeways: Why measures based on variance tell only half the story. Transportation Research Part A 42 (2008) 258-277

Van Wee, B., Rietveld, P., 2008. The Myth of Travel Time Saving: A Comment. Transport Reviews, 28: 6, 688-692.

Venables, A.J., 2007. Evaluating Urban Transport Improvements. Cost-Benefit Analysis in the Presence of Agglomeration and Income Taxation. Journal of Transport Economics and Policy, Volume 41, Part 2, May 2007, pp. 173-188. 
Vickerman, R., 2007. Recent evolution of research into the wider economic benefits of transport infrastructure investments. Discussion Paper n²007-9, OECD-ITF Joint Transport Research Centre, Paris, 21 p.

Vickrey, W. (1963): "Pricing in urban and suburban transport". American Economic Review: Papers and Proceedings, 53 (2), p.452-465, May.

Vickrey, W.S., 1969. Congestion Theory and Transport Investment. American Economic Review, vol. 59(2), pp. 251-260.

Walters, A.A. 1961. The theory and measurement of private and social costs of highway congestion. Econometrica, 29, 676-697.

Welch, M., Williams, H., 1997. The sensitivity of transport investment benefits to the evaluation of small travel-time savings. Journal of Transport Economics and Policy, Vol. 31, No. 3 (Sep., 1997), pp. 231-254.

\section{APPENDIX}

Table 6: Detailed breakdown of time gains per area in London

\begin{tabular}{|l|l|r|r|r|r|}
\hline & \multicolumn{1}{|c|}{ unit } & Charged area & Inner area & Outer area & Total \\
\hline Pre-charge veh $\mathrm{km}$ & 000 per day & 1531 & 15100 & 32929 & 49560 \\
\hline Post-charge veh $\mathrm{km}$ & 000 per day & 1276 & 14722 & 32708 & 48706 \\
\hline Reduction in veh km & 000 per day & 255 & 378 & 221 & 854 \\
\hline Veh hours saved per day & hours per day & 11953 & 14245 & 5812 & 32010 \\
\hline Time saved per veh km & minutes & 0.59 & 0.06 & 0.01 & \\
\hline value of time vehicle & pence per min & 51 & 37 & 29 & \\
\hline time gains & £ per day & 365762 & 316239 & 101129 & 783130 \\
\hline time gains & million $£$ per year & 93 & 81 & 26 & 200 \\
\hline \multicolumn{1}{|c|}{ in euros $(1 £=1.45 €)$} & & & & & \\
\hline value of time vehicle & $€$ per hour & 44 & 32 & 25 & \\
\hline time gains & $€$ per day & 530355 & 458547 & 146637 & 1135538 \\
\hline time gains & million $€$ per year & 135 & 117 & 37 & 290 \\
\hline
\end{tabular}

(source : Tfl, 2007 and authors calculation) 